\section{(6) OPEN ACCESS}

\title{
Amelioration of experimental arthritis by stroke-induced immunosuppression is independent of $\mathrm{T}_{\text {reg }}$ cell function
}

\author{
Ingo M Irmler, ${ }^{1}$ Mieczyslaw Gajda, ${ }^{2}$ Thomas Kamradt $^{1}$
}

\begin{abstract}
Handling editor Tore K Kvien
- Additional material is published online only. To view please visit the journal online (http://dx.doi.org/10.1136/ annrheumdis-2013-204148).

${ }^{1}$ Institute of Immunology, University Hospital Jena, Jena, Germany

Institute of Pathology, University Hospital Jena, Jena, Germany
\end{abstract}

\section{Correspondence to} Professor Thomas Kamradt, Institute of Immunology, University Hospital Jena, Leutragraben 3, Jena 07743 Germany; immunologie@mti. uni-jena.de

Received 20 June 2013 Revised 15 October 2013 Accepted 24 November 2013 Published Online First 10 December 2013



CrossMark

To cite: Irmler IM Gajda M, Kamradt T. Ann Rheum Dis 2014;73: 2183-2191.

\section{ABSTRACT}

Objectives Clinical evidence suggests that neurological lesions can protect from arthritis. Acute cerebral ischaemia induces severe immunosuppression, resulting in enhanced susceptibility to infections. We aimed to determine if stroke-induced immunosuppression can ameliorate arthritis and to delineate the immunological mechanisms involved.

Methods Unilateral cerebral ischaemia was induced in mice by occlusion of one middle cerebral artery (MCAO) at different time points after induction of G6PI-induced arthritis in mice. Clinical and histological signs of arthritis were assessed. Regulatory T cells were specifically depleted by injection of diphtheria toxin into transgenic DEREG mice. Immunological correlates of MCAO were determined by flow cytometry and serological methods. Results MCAO reduced the clinical and histological signs of arthritis significantly. To be effective, stroke had to be induced during the induction phase or the early clinical stage of arthritis. MCAO induced a global loss of leucocytes. Despite the reduced absolute number of lymphocytes, the functional differentiation of $T$ helper cells into Th1/17 cells and the production of autoantibodies were unimpaired. Depletion experiments showed that regulatory $\mathrm{T}$ cells were dispensable for the protective effect of MCAO.

Conclusions MCAO ameliorates arthritis. The correlate of protection from arthritis is not the reduction of a particular pathogenic leucocyte subset or the preferential expansion or emergence of a protective cell population but the global reduction of leucocytes during arthritis.

\section{INTRODUCTION}

The immune system and the nervous system communicate continually. ${ }^{1}$ Neurotransmitters modulate innate and adaptive immune responses while cytokines modulate body temperature, mood and sleep. Acute cerebral ischaemia induces severe immunosuppression, ${ }^{2-6}$ resulting in enhanced susceptibility to respiratory and urinary tract infections, which are the leading cause of death in stroke patients. ${ }^{4-8}$ Stroke-induced tissue destruction and disruption of the blood-brain barrier also result in the release of CNS autoantigens and their presentation to T-lymphocytes under proinflammatory immunogenic conditions. ${ }^{4} 69$ It has, therefore, been suggested that stroke-induced immunosuppression protects from stroke-induced autoimmune responses against CNS autoantigens. ${ }^{4}$ Autoimmune responses are essential in the pathogenesis of rheumatic diseases such as rheumatoid arthritis and spondyloarthropathies. ${ }^{10}{ }^{11}$ Clinical evidence suggests that ischaemic, traumatic or postinfectious damage to the nervous system can protect from or ameliorate arthritis. ${ }^{12-17}$ However, the underlying mechanisms have remained enigmatic.

The aims of this study were to examine if stroke-induced immunosuppression can ameliorate arthritis and to delineate the immunological mechanisms involved.

\section{MATERIALS AND METHODS}

Mice and induction of glucose-6-phosphate isomerase-induced arthritis

$\mathrm{DBA} / 1$ and DBA/1 DEREG mice were bred and underwent experiments at the animal facility of the University Hospital Jena. All animal studies were approved by the appropriate authorities (reg. No. 02-006/08). Arthritis was induced by subcutaneous immunisation with $200 \mu \mathrm{g}$ of recombinant human G6PI in complete Freund's adjuvant (Sigma-Aldrich, Taufkirchen, Germany) and evaluated clinically as described. ${ }^{18}$ Depletion of regulatory T cells $\left(\mathrm{T}_{\mathrm{reg}}\right)$ was performed in DBA/1 DEREG mice ${ }^{19}$ by intraperitoneal application of $0.5 \mu \mathrm{g}$ of diphtheria toxin 48 and $24 \mathrm{~h}$ before and 4 and $5 \mathrm{~d}$ after G6PI immunisation. This resulted in reliable transient depletion of $T_{\text {reg }}$ cells (data not shown). For experiments analysing the time point of middle cerebral artery occlusion (MCAO) performance on arthritis severity, DBA/1 or non-depleted DBA/1 DEREG mice were used.

\section{Histopathological assessment of glucose-6-phosphate isomerase-induced arthritis}

Haematoxylin-eosin-stained sections of fixed and decalcified joints were evaluated by a pathologist. Inflammation and cartilage and bone destruction were graded as described before. ${ }^{20}$

\section{Middle cerebral artery occlusion}

MCAO was performed under isoflurane anaesthesia. A nylon monofilament coated with silicone (Heraeus Kulzer, Hanau, Germany) was introduced into the common carotid artery and moved to the origin of the middle cerebral artery (MCA) to block perfusion. The filament was left in this position for $60 \mathrm{~min}$. In sham-operated animals, it was immediately withdrawn $4-5 \mathrm{~mm}$ to prevent brain ischaemia. After MCAO, mice were kept in heated cages, and $3 \mathrm{~d}$ before surgery Enrofloxacin $(25 \mathrm{mg} / \mathrm{mL}$; Bayer HealthCare, Leverkusen, Germany) was added to the drinking water. 
Enzyme-linked immunosorbent assay (ELISA)

Single-cell suspensions were prepared from spleens and lymph nodes (LN) (inguinal, axillary, paraaortic) and cultured in medium alone or with $25 \mu \mathrm{g}$ huG6PI or $2 \mu \mathrm{g}$ plate-bound anti-CD3 and $2 \mu \mathrm{g}$ anti-CD28. Supernatants were harvested and concentrations of IFN- $\gamma$, TNF- $\alpha$, IL-4, IL-5, IL-6 and IL-17 were measured by sandwich ELISAs (eBiosciences, Frankfurt, Germany) using recombinant cytokines (Peprotech, Hamburg, Germany) as standard. G6PI-specific antibody serum concentrations were determined as previously described. ${ }^{21}$

\section{Proliferation assay}

Single-cell suspensions from draining $\mathrm{LN}$ were prepared $9 \mathrm{~d}$ after immunisation and cultured with medium alone or $25 \mu \mathrm{g} /$ $\mathrm{mL}$ G6PI for $72 \mathrm{~h}$. $\left[{ }^{3} \mathrm{H}\right]$-thymidine $(0.5 \mu \mathrm{Ci} /$ well; Hartmann Analytic) per well was added for the last $18 \mathrm{~h}$. Cells were harvested, and incorporation of radiolabelled thymidine was measured using a microplate scintillation luminescence counter (Canberra-Packard, Rüsselsheim, Germany). The stimulation index (SI) was calculated as described. ${ }^{22}$

\section{Flow cytometric analysis of cell populations and cytokine production}

Single-cell suspensions from spleen and draining LN were prepared $9 \mathrm{~d}$ after immunisation and cultured with anti-CD16/32 $(2.4 \mathrm{G} 2)$ and rat $\mathrm{IgG}$ to prevent unspecific binding, followed by fluorochrome-conjugated antibodies directed against B220 (RA3-6B2), CD3, CD4, CD8, Gr-1, CD11b (all from eBioscience) or CD11c (M1/70).

Analysis of G6PI-specific cytokine-producing $\mathrm{T}$ cells was performed after culturing for $6 \mathrm{~h}$ with $25 \mu \mathrm{g} / \mathrm{mL}$ G6PI or medium alone as described. ${ }^{23-25}$ Data were acquired using a LSRII flow cytometer (Becton Dickinson, Heidelberg, Germany) and analysed using FlowJo V.8.1.1 software (Tree Star, Ashland, Oregon, USA). Gates for CD154 were set using unstimulated control samples.

\section{Statistical analysis}

Statistical differences between groups were evaluated using the non-parametric Mann-Whitney U test. Statistical significance was accepted for $\mathrm{p}$ values of less than $0.05 \quad(* \mathrm{p}<0.05$; $*$ * $<<0.01 ; * * \mathrm{p}<0.001)$. All calculations were performed using the SPSS software V.16.0 (SPSS Inc, Chicago, Illinois, USA). Data are presented as arithmetic mean and SE of the mean.

\section{RESULTS}

\section{MCAO-induced ischaemia}

Temporary occlusion of the middle cerebral artery (MCAO) induced substantial necrosis in the parietal lobe supplied by this vessel. Ischaemia was observable macroscopically in the left hemisphere, whereas the contralateral hemisphere was not affected (figure 1A). Histological sections revealed disbandment of cortical structures in the ischaemic brain areas (figure 1B) and extensive necrosis (figure 1C).

\section{MCAO ameliorates arthritis}

To evaluate the effects of stroke-induced immunosuppression at different stages of arthritis pathogenesis, stroke was induced at various time points after G6PI immunisation. MCAO 3 days before G6PI immunisation (d-3) had no effect on incidence or severity of arthritis (figure 2A). MCAO 3 days after immunisation with antigen in CFA resulted in an unacceptably high mortality rate (data not shown). In contrast, MCAO 6 days after immunisation (d6) ameliorated the course of arthritis significantly (figure 2B). MCAO 10 days after G6PI immunisation, when clinical signs of arthritis were already clearly visible, also reduced arthritis severity (figure $2 \mathrm{C}$ ). Stroke induction at later time points (d12, d15) had only minor effects on arthritis (data not shown). Thus, stroke ameliorates the clinical course of arthritis when MCAO is performed in the induction phase or during the early clinical stage of G6PI-induced arthritis.

Mice that had undergone MCAO or sham surgery 6 days after G6PI immunisation were examined histopathologically $16 \mathrm{~d}$ after G6PI immunisation. Paws from animals with experimental stroke had diminished signs of acute and chronic inflammation. They also had less cartilage and bone destruction compared with animals of the sham group, confirming the clinical scoring (figure 2D).

\section{MCAO induces a profound and prolonged loss of leucocytes}

To determine the immunological correlates of protection, we examined the effect of stroke on the number of leucocytes within the secondary lymphoid organs. At day 16 after G6PI immunisation ( $10 \mathrm{~d}$ after MCAO), when arthritis severity was maximal in control mice, we found significantly reduced cell numbers in $\mathrm{LN}$ and spleens of MCAO mice (figure $3 \mathrm{~A}$ ). Flow cytometric analyses revealed that the reduction of cell numbers was not caused by the loss of a particular cell population. The numbers of $\mathrm{B} 220^{+} \mathrm{B}$ cells, $\mathrm{CD} 3{ }^{+} \mathrm{CD} 4^{+} \mathrm{T}$ helper cells, $\mathrm{CD}^{+} \mathrm{CD}^{+}$cytotoxic $\mathrm{T}$ cells, as well as macrophages $\left(\mathrm{CD} 11 \mathrm{~b}^{+}\right)$, dendritic cells $\left(\mathrm{CD} 11 \mathrm{c}^{+}\right)$and neutrophil granulocytes $\left(\mathrm{Gr}-1^{+}\right.$), were all reduced significantly by $45-75 \%$ (figure 3B). Thus, amelioration of arthritis was associated with a massive and prolonged global loss of leucocytes. Adoptive transfer of $10^{7}$ unseparated cells from LN and spleens from G6PI-immunised mice 2 days after MCAO did not reconstitute disease development (data not shown).

\section{MCAO does not affect autoantibody production}

Autoantibodies against G6PI are necessary but not sufficient for induction of G6PI-induced arthritis. ${ }^{18} 212627$ Sixteen days after G6PI immunisation, titres of G6PI-specific IgG1, IgG2a, IgG2b, IgG3 and IgM antibodies were slightly but not significantly reduced in the MCAO group (figure 4A). Therefore, stroke-induced dampening of the humoral immune response does not explain the reduced arthritis severity in MCAO mice.

\section{Cytokine production is similar in MCAO and control mice}

Sixteen days after G6PI immunisation ( $10 \mathrm{~d}$ after MCAO), proliferation in response to G6PI was similar in cells from the draining LN of MCAO or sham-operated mice (figure 4B). Concentrations of IL-6, IL-17, IFN- $\gamma$ and TNF- $\alpha$ in the supernatants of LN cells were similar in both groups in response to stimulation with G6PI or anti-CD3/CD28 (figure 4C). Concentrations of IL-4 and IL-5 were near the detection limit in both groups.

\section{Functional differentiation of G6PI-specific Th cells is unimpaired after MCAO}

TNF- $\alpha$, IL-17 and IFN- $\gamma$ are key cytokines in the pathogenesis of G6PI-induced arthritis. ${ }^{18} 2829$ We analysed the G6PI-specific Th cell cytokine production $10 \mathrm{~d}$ after immunisation in mice that had undergone MCAO or sham surgery at d6 after G6PI immunisation. The number of $\mathrm{LN}$ and spleen cells did not differ between MCAO and sham animals at this time point (figure 5A). We used polychromatic flow cytometry to analyse the functional differentiation of G6PI-specific Th cells $10 \mathrm{~d}$ after immunisation. We found no difference in the numbers of 
Figure 1 Stroke induced by middle cerebral artery occlusion (MCA0). (A) MCAO resulted in extensive ischaemia in the parietal and temporal telencephalon (arrow) supplied by this vessel. ( $B$ and $C$ )

Haematoxylin-and-eosin staining revealed massive ischaemic tissue damage in the left hemisphere (red rectangle). The contralateral hemisphere is not affected (blue rectangle). Original magnifications $\times 40$ (B) or $\times 200$ (C).


total $\mathrm{CD}^{+}{ }^{+}$Th cells or G6PI-specific $\mathrm{CD} 4{ }^{+} \mathrm{CD} 154^{+}$cells in $\mathrm{MCAO}$ and sham mice (figure 5B). The numbers of IFN- $\gamma$, TNF- $\alpha$ or IL-17-producing G6PI-specific $T$ cells were also similar in control and MCAO mice (figure 5C). Thus, differentiation towards a Th1 or Th17 phenotype was unimpaired following stroke.

\section{$T_{\text {reg }}$ cells are dispensable for stroke-induced immunosuppression}

$\mathrm{CD} 4{ }^{+} \mathrm{CD} 25^{+} \mathrm{FoxP}^{+}$regulatory $\mathrm{T}$ cells have been shown to be relevant for the prevention and down-modulation of experimental arthritis. ${ }^{25}$ 31-34 An increased frequency of $\mathrm{T}_{\text {reg }}$ cells was reported 4 days after experimental stroke. ${ }^{35}$ Moreover, $\mathrm{T}_{\text {reg }}$ cells have been claimed as major modulators of postischaemic inflammatory brain damage. ${ }^{36}$ We employed DEREG mice, in which Foxp $3^{+}$regulatory $\mathrm{T}$ cells can be depleted by injecting diphtheria toxin, ${ }^{19}$ to examine the relevance of $\mathrm{T}_{\text {reg }}$ cells for the MCAO-induced amelioration of arthritis. Depletion of regulatory $\mathrm{T}$ cells resulted in enhanced severity and chronicity of G6PI-induced arthritis (figure 6A), confirming our earlier findings. ${ }^{25} \mathrm{MCAO}$ reduced clinical arthritis in $\mathrm{T}_{\text {reg }}$-cell-depleted
DEREG mice significantly compared with sham-operated mice. Arthritis severity was significantly reduced in both DBA/1 DEREG mice and non-transgenic littermates upon MCAO without a difference between these groups. $\mathrm{T}_{\text {reg }}$ cells and other cells produce the anti-inflammatory cytokine TGF- $\beta$. Serum concentrations of TGF- $\beta$ can be modulated by the sympathetic nervous system (SNS). ${ }^{37}$ We, therefore, examined TGF- $\beta$ serum concentrations 16 and $25 \mathrm{~d}$ after GPI immunisation. There was no difference between mice that had undergone MCAO $6 \mathrm{~d}$ after G6PI immunisation and sham-operated mice (data not shown). Thus, stroke-induced immunosuppression protects from arthritis even in the absence of $\mathrm{T}_{\text {reg }}$ cells and independently of increased TGF- $\beta$ production.

\section{MCAO does not induce increased numbers of regulatory $T$ cells in arthritic mice}

We used green fluorescent protein (GFP) expression by $\mathrm{T}_{\text {reg }}$ cells in the DEREG mouse $\operatorname{strain}^{19}$ to determine the frequency of $\mathrm{T}_{\text {reg }}$ cells during the course of experimental arthritis. There was no difference between MCAO and sham-operated animals. Approximately $5 \%$ of $\mathrm{CD}^{+} \mathrm{T}$ cells were $\mathrm{GFP}^{+} \mathrm{T}_{\text {reg }}$ before 
A MCAO d-3

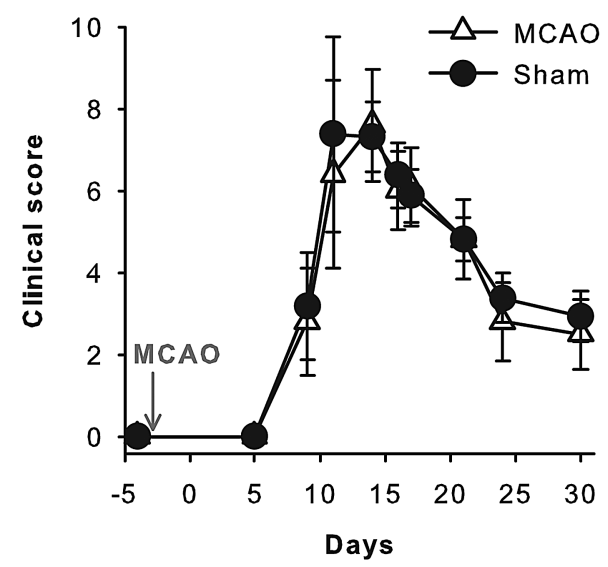

\section{MCAO d10}

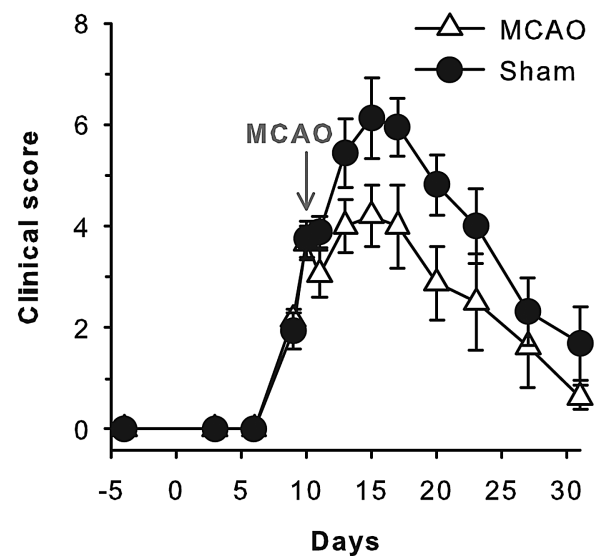

B MCAO d6

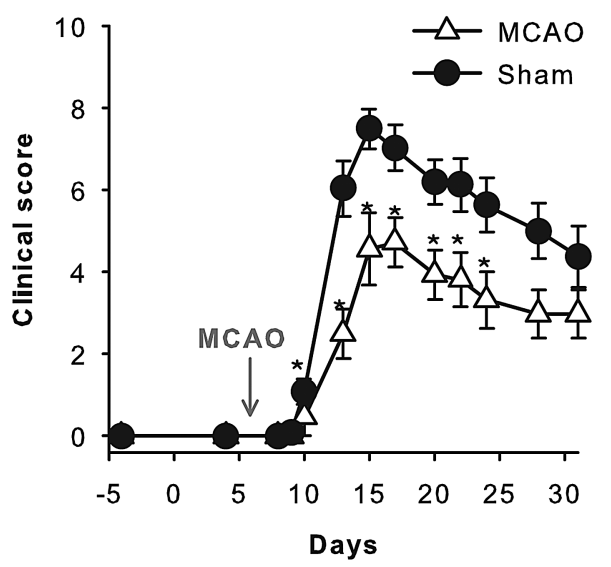

D Histopathology

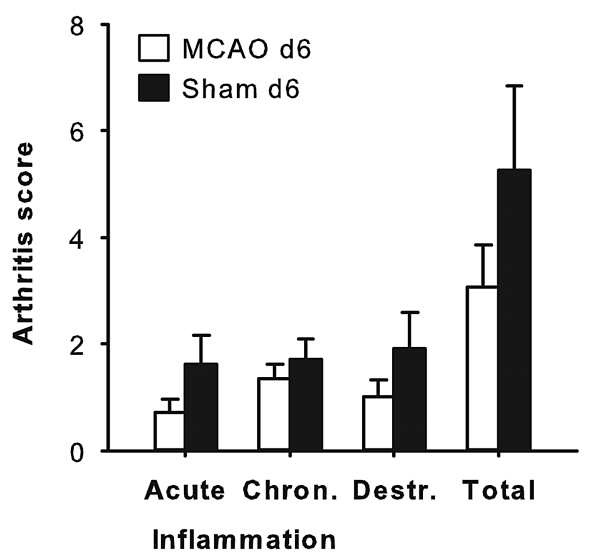

Figure 2 Middle cerebral artery occlusion (MCA0) ameliorates arthritis. (A) MCAO three days before G6PI immunisation (d-3) did not affect arthritis in MCAO (open triangles) and sham (filled circles) groups ( $n=9$ per group; one of two experiments with similar results is shown). ( $B$ and $C$ ) MCA0 $6 \mathrm{~d}(\mathrm{~B})$ or $10 \mathrm{~d}(\mathrm{C})$ after immunisation decreased arthritis severity ( $\mathrm{n}=8-9$ per group; for MCA0 d6, one of six experiments with similar results is shown). (D) Histopathological scoring of MCAO d6 animals $16 \mathrm{~d}$ after immunisation revealed decreased inflammation and joint destruction ( $\mathrm{n}=9$ per group). ( $\left.{ }^{*} p<0.05\right)$.

day 15 . When acute arthritis was already resolving $25 \mathrm{~d}$ postimmunisation, the frequency of $\mathrm{T}_{\text {reg }}$ cells was $9.9 \%$ in the MCAO group and $12.7 \%$ in the sham group, respectively (figure $6 \mathrm{~B}$ ). Therefore, the resolution of arthritis was associated with an increase in $\mathrm{T}_{\text {reg }}$ cells, but this increase was not further enhanced by MCAO.

\section{DISCUSSION}

Stroke-induced immunosuppression is a major pathogenic factor predisposing patients for morbidity and mortality through secondary infections, particularly pneumonia. ${ }^{2-4}$ 6-8 Anecdotal clinical evidence has suggested that stroke or denervation can protect from arthritis. ${ }^{12-17}$ We show here that stroke-induced immunosuppression modulates the pathogenic immune responses that induce autoimmune arthritis.

The main ex vivo correlate of stroke-induced protection from arthritis was a global reduction in leucocyte numbers. Reduced lymphocyte numbers in secondary lymphatic organs 567353940 and the peripheral blood $^{39}$ are characteristics of stroke in murine models. Several studies have demonstrated that this lymphocyte loss was due to apoptosis. 7539 Offner et al $^{35}$ reported a reduction in splenic cell yield already $22 \mathrm{~h}$ after stroke. This differs from our findings: we did not find dramatically reduced cell numbers in spleen and $\mathrm{LN} 4 \mathrm{~d}$ after MCAO; instead we found a massive reduction in leucocyte numbers $10 \mathrm{~d}$ after MCAO. Moreover, we found an approximately twofold reduction in spleen cell numbers, whereas Offner $e t a l^{35}$ reported an approximately fivefold reduction. These differences are explicable by several factors. First, we induced MCAO $6 \mathrm{~d}$ after immunisation with G6PI in CFA, that is, during an ongoing immune response when T-lymphocytes and B-lymphocytes proliferated in the draining LN and spleen. In contrast, Offner et al analysed unimmunised mice after MCAO. The ongoing activation and proliferation is likely to influence both the cells' susceptibility to stroke-induced apoptosis and the time needed to replenish the lymphocyte pool. Second, we studied DBA/1 mice, whereas Offner et al used C57BL/6 mice. Mouse strains differ in their susceptibility to stroke-induced immunosuppression. ${ }^{41}$ In addition to global leucocyte numbers, we also analysed the antigen-specific immune responses to G6PI, the autoantigen inciting the arthritogenic immune responses in G6PI-induced arthritis. ${ }^{18} 30$ There are several novel aspects in the current study of stroke-induced immunosuppression. B cell numbers were significantly reduced in mice in which arthritis was ameliorated after MCAO. In contrast, G6PI-specific antibody titres were not reduced in these 



B
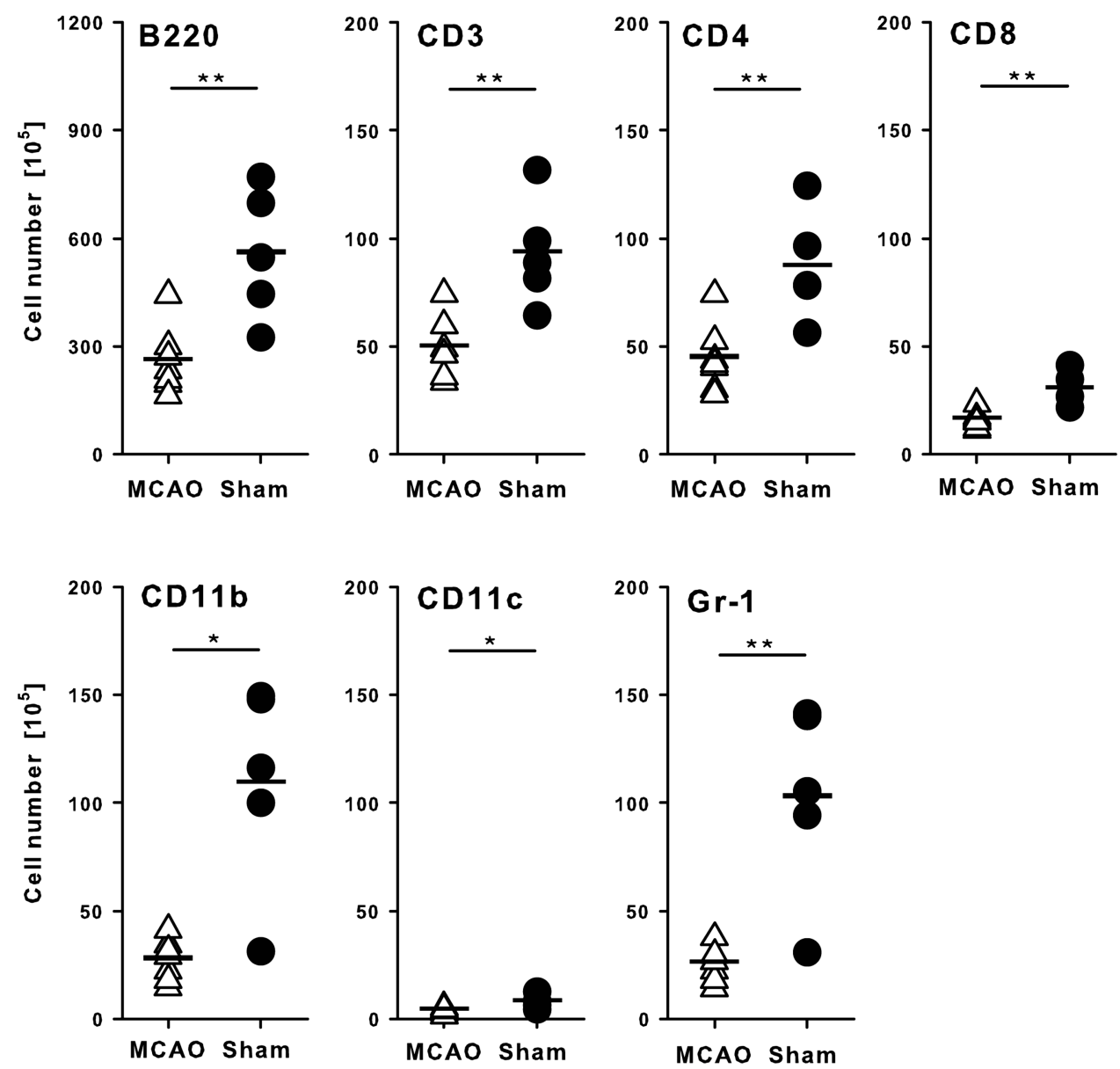

Figure 3 Reduction of leucocyte numbers by middle cerebral artery occlusion (MCAO). (A) Cell counts in spleen and lymph nodes $16 \mathrm{~d}$ after G6PI immunisation in mice that had undergone MCAO 10 days before. (B) Flow cytometric analyses of leucocyte subsets in the spleen revealed no preferential loss of a particular leucocyte population $\left({ }^{*} \mathrm{p}<0.05 ;{ }^{* *} \mathrm{p}<0.01 ;{ }^{* * *} \mathrm{p}<0.001\right)$.

animals, reflecting the fact that most of the antibody production had occurred prior to the stroke-induced B cell loss and confirming our earlier findings that antibodies are not sufficient to induce G6PI-induced arthritis. ${ }^{18} 21$

Studies on stroke patients reported reduced numbers and function of lymphocytes in the blood, whereas granulocyte numbers were increased, unaltered or not reported. ${ }^{2} 6-838$

The published data on the influence of stroke on T-cell cytokine production is contradictory. One study reported an initial hyperinflammatory reaction characterised by an increased production of proinflammatory cytokines preceding the stroke-induced immunosuppression in mice. ${ }^{42} \mathrm{~A}$ Th1/Th2 shift following clinical ${ }^{43}$ or experimental $^{39}$ stroke was reported, whereas another study found unimpaired production of TNF- $\alpha$ and IL- 6 in T cells from stroke patients. ${ }^{44}$ One possible explanation for these contradictory findings is that global ELISAs were used in those studies. Using flow cytometry, antigen-specific Th cells can be identified by their expression of CD154 upon a brief ex vivo stimulation with their cognate antigen. ${ }^{21} 23-252945-47$ Ten days after immunisation with G6PI, we found similar numbers of G6PI-specific CD4 ${ }^{+}$CD $154^{+}$ 
Figure 4 Humoral and cellular immune responses in arthritic animals (d16) $10 \mathrm{~d}$ after middle cerebral artery occlusion (MCAO). (A) Serum levels of G6PI-specific antibodies $(n=5-6$ per group) (B) Stimulation of lymph node cells with G6PI showed no difference in cell proliferation. (C) Cytokine levels in supernatants of lymph node cells cultured with G6PI ( $n=5$ per group).
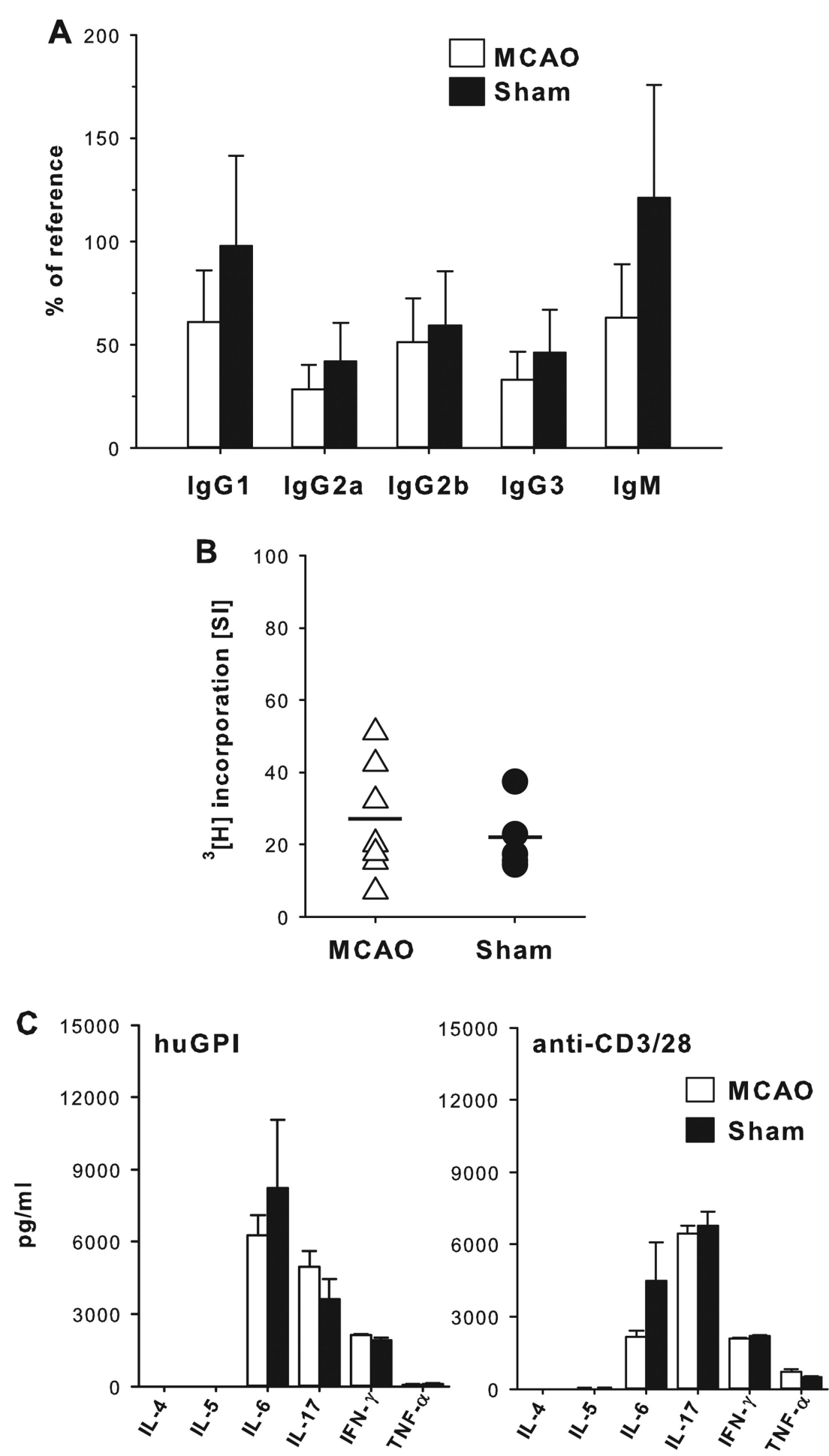

Th cells in the draining LN from control mice and mice that had undergone MCAO. Moreover, the number of cytokine-producing $\mathrm{CD} 4{ }^{+} \mathrm{CD} 154^{+} \mathrm{G} 6 \mathrm{PI}-$ specific Th cells was similar in MCAO mice and controls. Therefore, the proliferation of antigen-specific Th cells and the acquisition of Th cell effector functions are unaltered after MCAO.

$\mathrm{CD} 4{ }^{+} \mathrm{CD} 25^{+} \mathrm{FoxP}^{+}$regulatory $\mathrm{T}$ cells maintain immune homeostasis by suppressing immune responses to self and non-self antigens. ${ }^{48}$ An increased frequency of $\mathrm{T}_{\text {reg }}$ cells has been reported in patients for up to 3 weeks after stroke. ${ }^{49} \mathrm{~T}_{\text {reg }}$ cell frequencies were also increased in unimmunised mice $96 \mathrm{~h}$ after MCAO. ${ }^{35}$ Due to the massive loss of lymphocytes, absolute $\mathrm{T}_{\text {reg }}$ cell numbers were nevertheless strongly decreased in MCAO mice in that study. ${ }^{35}$ In contrast to these findings, we did not find an increase in $\mathrm{T}_{\text {reg }}$ cells in MCAO mice. One important difference between our study and the earlier study ${ }^{35}$ is that we examined the consequences of MCAO in mice with an ongoing autoimmune response. We found increased $\mathrm{T}_{\text {reg }}$ cell frequencies during the remission phase of arthritis both in MCAO and control mice. This increased $\mathrm{T}_{\text {reg }}$ cell frequency was not further enhanced by MCAO. Whether $\mathrm{T}_{\text {reg }}$ cells contribute to the systemic stroke-induced immunosuppression has not been 



Figure 5 Unperturbed expansion and functional differentiation of G6PI-specific Th cells at the onset of clinical arthritis. (A) The number of spleen and lymph node cells $10 \mathrm{~d}$ after G6PI-immunisation was not different in middle cerebral artery occlusion (MCA0) and sham mice. (B) The number of $\mathrm{CD}^{+}$Th cells and G6PI-specific CD4 ${ }^{+} \mathrm{CD} 154^{+}$Th cells was unaltered in MCAO mice as compared with sham controls. (C) Expression of IL-17, TNF- $\alpha$ and IFN- $\gamma$ in G6PI-specific CD4 ${ }^{+} \mathrm{CD} 154^{+} \mathrm{T}$ cells was similar in both groups.

analysed to date. Using a genetic model of $\mathrm{T}_{\text {reg }}$ cell depletion, we found that $T_{\text {reg }}$ cells were dispensable for the arthritis-ameliorating effect of experimental stroke.

How does stroke mediate these immunomodulatory effects? Two immediate candidates are the hypothalamic-pituitaryadrenal axis and the SNS, both of which are known to be immunosuppressive and activated in response to stroke. ${ }^{39}$ An elegant experimental study showed that both SNS-blockade with Propranolol or application of the glucocorticoid receptor antagonist RU486 prevented the apoptosis-induced decrease in lymphocyte counts. Yet, only Propranolol but not RU486 prevented bacteraemia and pneumonia and improved survival in MCAO mice. ${ }^{39}$ Thus, activation of the SNS seems to be a major mechanism for stroke-induced immunosuppression. Confirming 

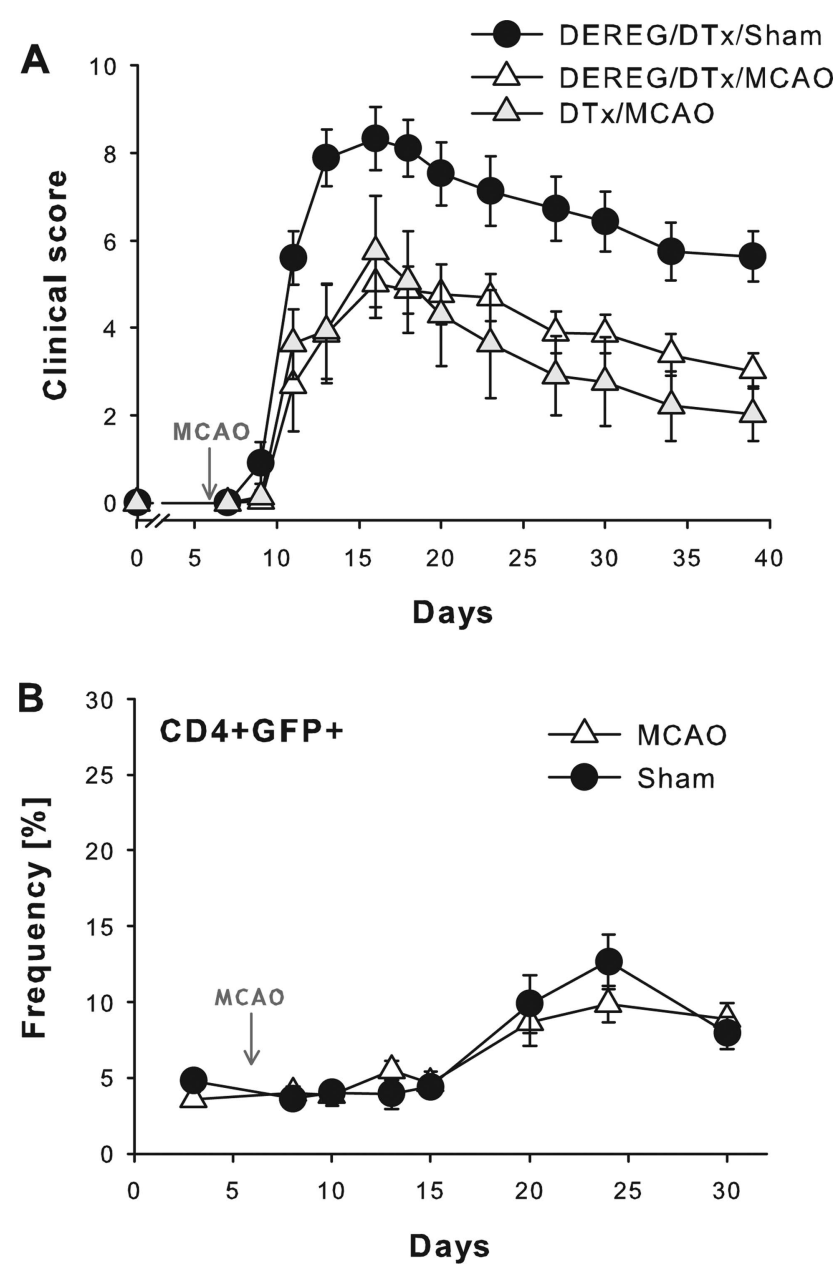

Figure $6 T_{\text {reg }}$ cells are dispensable for the immunosuppressive effect of middle cerebral artery occlusion (MCAO). (A) Depletion of $T_{\text {reg }}$ cells in DEREG mice resulted in chronic inflammatory G6PI-induced arthritis (DEREG/DTx/sham). Disease severity upon MCAO was similar in DTx-treated DEREG mice that lacked $\mathrm{T}_{\text {reg }}$ cells (DEREG/DTx/MCAO) and in non-transgenic littermates (DTx/MCAO) that contained normal numbers of $\mathrm{T}_{\text {reg }}$ cells. From day 9 to 39 of clinical arthritis, statistical significance $(p<0.05)$ for differences in arthritis severity was achieved with the exception of day 23 between DEREG/DTx/MCAO and DEREG/ DTx/sham, whereas $p>0.05$ for DEREG/DTx/MCAO and DTx/MCAO mice. (B) Frequency of $\mathrm{GFP}^{+} \mathrm{T}_{\text {reg }}$ cells in $\mathrm{CD}^{+}$blood cells was similar in MCAO and sham animals after experimental stroke.

and extending these findings, we have found that chemical sympathectomy with 6-hydroxydopamine (6-OHDA) prevents G6PI-induced arthritis (Müller et al, manuscript in preparation).

\section{CONCLUSION}

Experimental stroke causes a global loss of leucocytes and ameliorates arthritis. The correlate of protection from arthritis is not the reduction of a particular, pathogenic leucocyte subset or the preferential expansion or emergence of a protective cell population but the global reduction of leucocytes during arthritis.

Acknowledgements The authors thank Dr. Tim Sparwasser (Institute of Infection Immunology, TWINCORE, Hannover, Germany) for DEREG mice, Dipl. Ing. Ronald Naumann (MPI of Molecular Cell Biology and Genetics, Dresden, Germany) for speed-congenic back-cross of the DEREG mice onto the DBA/1 strain, Dr. Sylvia Heink (Institute of Immunology, University Hospital Jena, Jena, Germany) for help with mouse-typing and Dr. Andreas Meisel (Department of Neurology, Charité University Hospital Berlin, Germany) for introduction to the MCAO technique. We further thank Claudia Doering for technical assistance in histopathology and Annett Krause for organisational assistance.

Contributors TK conceived of the concept. II performed experiments and analysed data. MG did and interpreted histopathological studies. IMI and TK designed the studies, interpreted data and drafted the manuscript. All authors read and approved the final manuscript.

Funding This work was supported by the BMBF (IMMUNOPAIN programme "Neuroimmune connections in inflammation and pain", TP 6 "NeuroImmunomodulation of Arthritis" (01EC1004B to TK). Federal Ministry of Education and Research.

Competing interests None.

Provenance and peer review Not commissioned; externally peer reviewed.

Open Access This is an Open Access article distributed in accordance with the Creative Commons Attribution Non Commercial (CC BY-NC 3.0) license, which permits others to distribute, remix, adapt, build upon this work non-commercially, and license their derivative works on different terms, provided the original work is properly cited and the use is non-commercial. See: http://creativecommons.org/ licenses/by-nc/3.0/

\section{REFERENCES}

1 Steinman L. Elaborate interactions between the immune and nervous systems. Nat Immunol 2004;5:575-81.

2 Czlonkowska A, Cyrta B, Korlak J. Immunological observations on patients with acute cerebral vascular disease. J Neurol Sci 1979;43:455-64.

3 Woiciechowsky C, Asadullah K, Nestler D, et al. Sympathetic activation triggers systemic interleukin-10 release in immunodepression induced by brain injury. Nat Med 1998:4:808-13.

4 Dirnagl U, Klehmet J, Braun JS, et al. Stroke-induced immunodepression: experimental evidence and clinical relevance. Stroke 2007;38:770-3.

5 Offner $H$, Vandenbark AA, Hurn PD. Effect of experimental stroke on peripheral immunity: CNS ischemia induces profound immunosuppression. Neuroscience 2009;158:1098-111.

6 Chamorro A, Meisel A, Planas AM, et al. The immunology of acute stroke. Nat Rev Neurol 2012;8:401-10.

7 Haeusler KG, Schmidt WU, Fohring F, et al. Cellular immunodepression preceding infectious complications after acute ischemic stroke in humans. Cerebrovasc Dis 2008;25:50-8

8 Klehmet J, Harms H, Richter M, et al. Stroke-induced immunodepression and post-stroke infections: lessons from the preventive antibacterial therapy in stroke trial. Neuroscience 2009;158:1184-93.

9 Ren X, Akiyoshi K, Grafe MR, et al. Myelin specific cells infiltrate MCAO lesions and exacerbate stroke severity. Metab Brain Dis 2012;27:7-15.

10 McInnes IB, Schett $G$. The pathogenesis of rheumatoid arthritis. N Engl J Med 2011;365:2205-19.

11 Kamradt T, Mitchison NA. Tolerance and autoimmunity. N Engl J Med 2001;344:655-64.

12 Jacqueline F. A case of evolutive polyarthritis with localisation contralateral to a hemiplegia. Rev Rhum Mal Osteoartic 1953;20:323-4

13 Thompson M, Bywaters EG. Unilateral rheumatoid arthritis following hemiplegia. Ann Rheum Dis 1962;21:370-7.

14 Kamermann JS. Protective effect of traumatic lesions on rheumatoid arthritis. Ann Rheum Dis 1966;25:361-3.

15 Veale $D$, Farrell M, Fitzgerald 0 . Mechanism of joint sparing in a patient with unilateral psoriatic arthritis and a longstanding hemiplegia. $\mathrm{Br} J$ Rheumatol 1993;32:413-16

16 Mulherin D, Bresnihan B, FitzGerald O. Digital denervation associated with absence of nail and distal interphalangeal joint involvement in psoriatic arthritis. J Rheumatol 1995;22:1211-12.

17 Kane D, Lockhart JC, Balint PV, et al. Protective effect of sensory denervation in inflammatory arthritis (evidence of regulatory neuroimmune pathways in the arthritic joint). Ann Rheum Dis 2005;64:325-7.

18 Schubert D, Maier B, Morawietz L, et al. Immunization with glucose-6-phosphate isomerase induces $T$ cell-dependent peripheral polyarthritis in genetically unaltered mice. J Immunol 2004;172:4503-9.

19 Lahl K, Loddenkemper C, Drouin C, et al. Selective depletion of Foxp3+ regulatory T cells induces a scurfy-like disease. J Exp Med 2007;204:57-63.

20 Irmler IM, Opfermann T, Gebhardt P, et al. In vivo molecular imaging of experimental joint inflammation by combined (18)F-FDG positron emission tomography and computed tomography. Arthritis Res Ther 2010;12:R203.

21 Frey 0 , Bruns L, Morawietz L, et al. B cell depletion reduces the number of autoreactive $T$ helper cells and prevents glucose-6-phosphate isomerase-induced arthritis. PLoS One 2011;6:e24718.

22 Lengl-Janssen $B$, Strauss $A F$, Steere $A C$, et al. The $T$ helper cell response in Lyme arthritis: differential recognition of Borrelia burgdorferi outer surface protein $A$ in 
patients with treatment-resistant or treatment-responsive Lyme arthritis. J Exp Med 1994;180:2069-78

23 Berod L, Heinemann C, Heink S, et al. PI3Kgamma deficiency delays the onset of experimental autoimmune encephalomyelitis and ameliorates its clinical outcome. Eur J Immunol 2011:41:833-44.

24 Frey 0, Meisel J, Hutloff A, et al. Inducible costimulator (ICOS) blockade inhibits accumulation of polyfunctional T helper $1 / \mathrm{T}$ helper 17 cells and mitigates autoimmune arthritis. Ann Rheum Dis 2010;69:1495-501.

25 Frey $\mathrm{O}$, Reichel $\mathrm{A}$, Bonhagen $\mathrm{K}$, et al. Regulatory $\mathrm{T}$ cells control the transition from acute into chronic inflammation in glucose-6-phosphate isomerase-induced arthritis Ann Rheum Dis 2010;69:1511-18.

26 Bockermann R, Schubert D, Kamradt T, et al. Induction of a B-cell-dependent chronic arthritis with glucose-6-phosphate isomerase. Arthritis Res Ther 2005;7: R1316-24.

27 Tanaka-Watanabe Y, Matsumoto I, Iwanami K, et al. B cells play a crucial role as antigen-presenting cells and collaborate with inflammatory cytokines in glucose-6-phosphate isomerase-induced arthritis. Clin Exp Immunol 2009;155:285-94.

28 Iwanami K, Matsumoto I, Tanaka-Watanabe Y, et al. Crucial role of the interleukin-6/interleukin-17 cytokine axis in the induction of arthritis by glucose-6-phosphate isomerase. Arthritis Rheum 2008;58:754-63.

29 Frey 0 , Mitera T, Kelchtermans $\mathrm{H}$, et al. Ameliorated course of glucose-6-phosphate isomerase (G6PI)-induced arthritis in IFN-gamma receptor knockout mice exposes an arthritis-promoting role of IFN-gamma. J Autoimmun 2011;36:161-9.

30 Bruns L, Frey O, Morawietz L, et al. Immunization with an immunodominant self-peptide derived from glucose-6-phosphate isomerase induces arthritis in DBA/1 mice. Arthritis Res Ther 2009;11:R117.

31 Morgan ME, Sutmuller RP, Witteveen HJ, et al. CD25+ cell depletion hastens the onset of severe disease in collagen-induced arthritis. Arthritis Rheum 2003:48:1452-60.

32 Huehn J, Siegmund K, Lehmann JC, et al. Developmental stage, phenotype, and migration distinguish naive- and effector/memory-like CD4+ regulatory T cells. J Exp Med 2004;199:303-13.

33 Nguyen LT, Jacobs J, Mathis D, et al. Where FoxP3-dependent regulatory T cells impinge on the development of inflammatory arthritis. Arthritis Rheum 2007:56:509-20.

34 Kelchtermans H, Geboes L, Mitera T, et al. Activated CD4+CD25+ regulatory T cells inhibit osteoclastogenesis and collagen-induced arthritis. Ann Rheum Dis 2009:68:744-50.
35 Offner H, Subramanian S, Parker SM, et al. Splenic atrophy in experimental stroke is accompanied by increased regulatory $T$ cells and circulating macrophages. J Immunol 2006:176:6523-31.

36 Liesz A, Suri-Payer E, Veltkamp C, et al. Regulatory T cells are key cerebroprotective immunomodulators in acute experimental stroke. Nat Med 2009:15:192-9.

37 Straub RH, Rauch L, Rauh L, et al. Sympathetic inhibition of IL-6, IFN- $\gamma$, and KC/ CXCL1 and sympathetic stimulation of TGF- $\beta$ in spleen of early arthritic mice. Brain Behav Immun. 2011;25:1708-15.

38 Vogelgesang A, Grunwald U, Langner S, et al. Analysis of lymphocyte subsets in patients with stroke and their influence on infection after stroke. Stroke 2008;39:237-41

39 Prass K, Meisel C, Hoflich C, et al. Stroke-induced immunodeficiency promotes spontaneous bacterial infections and is mediated by sympathetic activation reversal by poststroke $T$ helper cell type 1-like immunostimulation. J Exp Med 2003;198:725-36.

40 Gendron A, Teitelbaum J, Cossette C, et al. Temporal effects of left versus right middle cerebral artery occlusion on spleen lymphocyte subsets and mitogenic response in Wistar rats. Brain Res 2002;955:85-97.

41 Schulte-Herbruggen 0, Klehmet J, Quarcoo D, et al. Mouse strains differ in their susceptibility to poststroke infections. Neuroimmunomodulation 2006;13:13-18.

42 Offner $H$, Subramanian S, Parker SM, et al. Experimental stroke induces massive, rapid activation of the peripheral immune system. J Cereb Blood Flow Metab 2006;26:654-65.

43 Theodorou GL, Marousi S, Ellul J, et al. T helper 1 (Th1)/Th2 cytokine expression shift of peripheral blood CD4+ and CD8+ T cells in patients at the post-acute phase of stroke. Clin Exp Immunol 2008;152:456-63.

44 Vogelgesang A, May VE, Grunwald U, et al. Functional status of peripheral blood T-cells in ischemic stroke patients. PLoS One 2010;5:e8718.

45 Chattopadhyay PK, Yu J, Roederer M. A live-cell assay to detect antigen-specific CD4+ T cells with diverse cytokine profiles. Nat Med 2005;11:1113-17.

46 Frentsch $M$, Arbach 0 , Kirchhoff $D$, et al. Direct access to CD4+ T cells specific for defined antigens according to CD154 expression. Nat Med 2005;11:1118-24.

47 Meier S, Stark R, Frentsch M. The influence of different stimulation conditions on the assessment of antigen-induced CD154 expression on CD4+ T cells. Cytometry A 2008;73:1035-42.

48 Wing JB, Sakaguchi S. Multiple treg suppressive modules and their adaptability. Front Immunol 2012;3:178.

49 Yan J, Read SJ, Henderson RD, et al. Frequency and function of regulatory $T$ cells after ischaemic stroke in humans. I Neuroimmunol 2012:243:89-94. 